\title{
Evaluasi Pengelolaan Obat Di Instalasi Farmasi Rumah Sakit Umum Daerah Provinsi NTB Tahun 2017
}

\section{Drug Management Evaluation in Pharmacy Department of NTB Province Regional Hospital during 2017 Period}

\author{
Nur Oktaviani, Gunawan Pamudji, Y.Kristanto \\ Universitas Setia Budi Surakarta \\ email : nuroktaviani8485@gmail.com
}

\begin{abstract}
Abstrak
IFRS bertugas dalam pengelolaan obat yaitu tahap seleksi, perencanaan dan pengadaan, distribusi dan penggunaan. Observasi pendahuluan menunjukkan permasalahan adanya beberapa item obat yang tidak terpakai yang mengakibatkan terjadinya obat kadaluarsa atau rusak di IFRSUD Provinsi NTB. Tujuan penelitian untuk mengevaluasi pengelolaan obat pada IFRSUD Provinsi NTB.

Rancangan penelitian deskriptif secara retrospektif dan concurrent. Data kuantitatif dan kualitatif, disertai wawancara pihak terkait. Indikator pada tiap tahap pengelolaan obat diukur menggunakan indikator Depkes RI, Pudjaningsih, Permenkes dan WHO dibandingkan penelitian lain.

Hasil penelitian menunjukkan bahwa pada beberapa tahap pengelolaan obat ada yang belum sesuai standar yaitu: Tahap seleksi, kesesuaian dengan formularium nasional (96,7\%), perencanaan pengadaan, persentase alokasi dana yang tersedia (10,98\%), persentase modal dana yang tersedia dari dana yang dibutuhkan (54,66\%), frekuensi kurang lengkapnya SP/Faktur (30 kali), frekuensi tertundanya pembayaran oleh rumah sakit (160 kali), persentase kesesuaian antara perencanaan dengan kenyataan pakai obat (120,64\%), distribusi, ketepatan data jumlah obat pada kartu stok (73\%), Turn Over Ratio (TOR) sebanyak (4,01 kali), persentase obat yang rusak/kadaluarsa $(2,8 \%)$, persentase stok mati $(4 \%)$, penggunaan, jumlah item obat perlembar resep (3,44 lembar), persentase antibiotik (11,78\%), persentase obat injeksi $(22,73 \%)$.. Hasil yang sesuai standar yaitu tahap seleksi: kesesuaian dengan formularium rumah sakit; pengadaan: frekuensi pengadaan tiap item obat pertahun dan secara EOQ; distribusi: tingkat ketersediaan obat; penggunaan: persentase peresepan generik, persentase obat yang diserahkan, persentase obat dilabeli lengkap dan rata-rata waktu yang digunakan melayani resep.
\end{abstract}

Kata kunci : Pengelolaan obat, Indikator, Instalasi Farmasi RSUD Provinsi NTB

\begin{abstract}
IFRS is responsible for drug management, namely selection, planning and procurement, distribution and use. Preliminary observations indicate of drug management problems in IFRSUD Province NTB. The aim of the study was to evaluate of drug management in IFRSUD Province NTB.

Descriptive research were taken retrospectively and concurrently. Data in the form of quantitative and qualitative, accompanied by interviews of related parties. All stages of drug management measured using the $\mathrm{MOH} \mathrm{RI}$ indicator, Pudjaningsih, Permenkes and WHO then compared with the results of other studies.

The results showed that the stage that did not meet the standards were: Selection, conformity with the national formulary $(96,7 \%)$, planning procurement, percentage of available fund allocation (10,98\%), namely the frequency of incomplete SP / Invoice (30 kali), percentage of available capital funds with the total needed $(54,66 \%)$, frequency of delay in payment by the hospital against the agreed time (160 kali), the percentage of suitability between drug planning and the reality of each drug $(120,64 \%)$, distribution, the accuracy of the amount of drug data on the automatic stock card of (73\%), Turn Over Ratio (TOR) as much (4,01 times), percentage and
\end{abstract}


value of drugs that were damaged / expired (2,8\%), percentage of dead stock $(4 \%)$, Usage, number of drug items per recipe (3,44 sheets), percentage of antibiotic $(11,78 \%)$, and percentage of prescription injection drugs $(22,73 \%)$.. The results are in accordance with the standards, the stage of selection suitability with hospital formulary; procurement: frequency of procurement of each drug item per year; distribution: namely drug availability level; use, percentage of prescription with a generic name, percentage of drugs that can submitted, percentage of drug that label, and the average time spent serving recipes.

Keywords: Drug Management, Indicators, Pharmacy Department of NTB Hospital.

\section{PENDAHULUAN}

Rumah sakit adalah Institusi pelayanan kesehatan yang menyelenggarakan pelayanan kesehatan perorangan secara paripurna yang menyediakan pelayanan rawat inap, rawat jalan, dan gawat darurat. Pelayanan kesehatan paripurna adalah pelayanan kesehatan yang meliputi promotif, preventif, kuratif, dan rehabilitatif, untuk mendukung hal tersebut Instalasi Farmasi Rumah Sakit bertugas agar melangsungkan pelayanan farmasi yang optimal, menyelenggarakan kegiatan pelayanan farmasi profesional berdasarkan prosedur kefarmasian dan etik profesi, melaksanakan Komunikasi, Informasi dan Edukasi (KIE), memberi pelayanan bermutu melalui analisa, dan evaluasi untuk meningkatkan mutu pelayanan farmasi, melakukan pengawasan berdasarkan aturanaturan yang berlaku, menyelenggarakan pendidikan dan pelatihan di bidang farmasi, mengadakan penelitian dan pengembangan di bidang farmasi, memfasilitasi dan mendorong tersusunnya standar pengobatan dan formularium rumah sakit (Depkes, 2009).

Pengelolaan obat berhubungan erat dengan anggaran dan belanja rumah sakit. Mengenai biaya obat di rumah sakit dapat sebesar $40 \%$ dari total biaya kesehatan. Menurut Depkes RI, secara nasional biaya obat sebesar $40 \%-50 \%$ dari jumlah operasional pelayanan kesehatan. Mengingat begitu pentingnya dana dan kedudukan obat bagi rumah sakit, maka pengelolaannya harus dilakukan secara efektif dan efisien sehingga dapat memberikan manfaat yang sebesar-besarnya bagi pasien dan rumah sakit. Siklus manajemen obat mencakup 4 tahap, yaitu : selection (seleksi), procurement (pengadaan), distribution (distribusi), dan use (penggunaan). Masingmasing tahap dalam siklus manajemen obat saling terkait sehingga harus dikelola dengan baik agar masing-masing dapat dikelola secara optimal. Tahapan yang saling terkait dalam siklus manajemen obat diperlukan suatu sistem suplai yang terorganisir agar kegiatan berjalan baik dan saling mendukung sehingga ketersediaan obat dapat terjamin yang mendukung pelayanan kesehatan dan menjadi sumber pendapatan rumah sakit yang potensial (Quick et al.,2012)

Evaluasi pengelolaan obat di Rumah Sakit Umum Daerah Provinsi NTB perlu dilaksanakan, karena evaluasi pengelolaan obat di IFRSUD 
Provinsi NTB belum pernah dilakukan. Berdasarkan observasi awal yang dilakukan, permasalahan yang sering terjadi di IFRS Provinsi NTB adalah pada tahap seleksi masih ada beberapa obat yang belum masuk Fornas dan tahap pengadaan masih kecilnya anggaran dana obat, dan masih tertundanya pembayaran tagihan oleh RSUD Provinsi NTB pada distributor obat sehingga menyebabkan pembelian obat tidak bisa dilaksanakan, pada tahap distribusi masih terdapat beberapa item obat yang tidak terpakai, serta masih terdapat beberapa yang kadaluarsa dan pada tahap penggunaan masih banyaknya penggunaan sediaan injeksi.

Ketidaklancaran pengelolaan obat dapat memberi dampak negatif terhadap rumah sakit, maka perlu dilakukan penelusuran terhadap gambaran pengelolaan dan manajemen pendukungnya agar dapat diketahui permasalahan sehingga dapat dilakukan upaya perbaikan dalam rangka meningkatkan pelayanan kesehatan kepada masyarakat. Depkes (2008) dalam Pedoman Supervisi Dan Evaluasi Obat Publik, Quick et al (2012), Pujaningsih (1996), Permenkes (2016) dan WHO (1993) dan menetapkan beberapa indikator pengelolaan obat. Sejumlah indikator pengelolaan obat yang dipilih dapat dilihat pada tabel I.

Dari hasil perhitungan dengan indikator tersebut kemudian dinilai apakah sudah sesuai standar pembanding indikator dan dari hasil berbagai hasil penelitian.

\section{METODE PENELITIAN}

Alat

Data primer dan terhadap data sekunder yang diambil dari dokumen dicatat dalam daftar cek atau mencatat langsung pada buku tulis. Pedoman wawancara, berupa daftar pertanyaan yang digunakan untuk mengumpulkan data primer dengan mewawancarai pihak yang terkait dengan pengelolaan obat.

\section{Bahan}

Data diambil dari data secara retrospektif pada tahun 2017 serta data pada saat penelitian (concurrent). Bahan penelitian meliputi data primer yang diperoleh dari observasi waktu pelayanan, kartu stok dan resep, sedangkan data sekunder diperoleh dari dokumen berupa laporan keuangan, laporan pembelian, surat pesanan, faktur obat, laporan persediaan obat, kartu stok, buku formularium rumah sakit dan formularium nasional, laporan penggunaan obat generik/obat Fornas dan Formularium Rumah Sakit, laporan perencanaan dan pemakaian obat tahunan, buku pembelian, laporan obat rusak/kadaluarsa, surat pesanan, daftar rekanan.

\section{Prosedur Penelitian}

Seleksi

Tahap seleksi di evaluasi menggunakan indikator kesesuaian item obat yang disediakan rumah sakit terhadap formularium nasional 2016 dan formularium rumah sakit.

\section{Perencanaan dan pengadaan}

Tahap perencanaan dan pengadaan di evaluasi dengan indikator persentase alokasi dana pengadaan obat yang tersedia, persentase modal dana yang 
tersedia dengan keseluruhan dana yang dibutuhkan, frekuensi kurang lengkapnya surat pesanan /faktur, frekuensi pengadaan tiap item obat pertahun, frekuensi tertundanya pembayaran oleh rumah sakit terhadap waktu yang disepakati, persentase kesesuaian antara perencanaan obat dengan masing -masing obat.

\section{Distribusi}

Tahap distribusi di evaluasi dengan indikator ketepatan data jumlah obat pada kartu stok, Turn Over Ratio (TOR), persentase dan nilai obat yang kadaluarsa dan atau rusak, persentase stok mati, tingkat ketersediaan obat.

\section{Penggunaan}

Tahap penggunaan di evaluasi dengan indikator jumlah item obat perlembar resep, persentase peresepan nama generik, persentase peresepan obat antibiotik, persentase peresepan obat injeksi, persentase obat yang dapat diserahkan, persentase obat yang dilabeli dengan lengkap, rata-rata waktu yang digunakan untuk melayani resep.

\section{Managemen pendukung}

Gambaran managemen

pendukung diperoleh dari pengamatan selama penelitian dan data-data pendukung yang terkait.

\section{Seleksi \\ HASIL DAN PEMBAHASAN}

Persentase kesesuaian obat yang tersedia dengan Fornas adalah 96,7\%. Menurut Kementrian Kesehatan bahwa persentase kesesuaian obat dengan Fornas adalah $100 \%$ sebagai pedoman penyediaan obat untuk BPJS di fasilitas kesehatan RS (Kemenkes, 2016) belum sesuai standar, dalam hal ini diperlukan ketelitian KFT dalam seleksi obat yang disesuaikan dengan formularium nasional. Persentase kesesuaian obat yang tersedia dengan Formularium Rumah Sakit adalah $86,1 \%$ sudah sesuai standar, menurut Permenkes untuk persyaratan akreditasi RS adalah 80\% (Permenkes, 2014), hal ini karena Formularium Rumah Sakit belum diperbaharui yang masih banyak terdapat obat-obat untuk pasien umum.

\section{Perencanaan dan pengadaan}

Persentase alokasi dana pengadaan obat yang tersedia

Persentase alokasi dana pengadaan obat yang tersedia tahun 2017 adalah 10,98\% belum efisien jika dibandingkan dengan nilai standar berkisar 30-40\% Depkes (2008).

Persentase modal dana yang tersedia dengan keseluruhan dana yang dibutuhkan

Persentase modal dana yang tersedia dengan keseluruhan dana yang dibutuhkan adalah $54,66 \%$ belum sesuai standar adalah $100 \%$ yang ditetapkan oleh Depkes (2008) dan dibandingkan dengan Penelitian Costa (2012) di RSUD Ungaran Kabupaten Semarang sebesar $100 \%$.

Frekuensi kurang lengkapnya Surat Pesanan /Faktur

Frekuensi kurang lengkapnya Surat Pesanan /Faktur adalah 30 kali, hal ini karena surat pesanan yang salah tidak langsung diperbaiki dan faktur yang salah ada yang terlewatkan untuk dikembalikan pada petugas PBF untuk diperbaiki, hal ini melebihi dari standar Pudjaningsih (1996) yaitu 1-9 kali. 
Tabel 1. Indikator Pengelolaan Obat di Rumah sakit

\begin{tabular}{|c|c|c|c|}
\hline Tahapan & Indikator & Tujuan & Nilai Pembanding \\
\hline \multirow[t]{2}{*}{ Seleksi } & $\begin{array}{l}\text { 1.Kesesuaian item obat } \\
\text { yang tersedia } \\
\text { Formularium Nasional. }\end{array}$ & $\begin{array}{l}\text { Untuk mengetahui jumlah obat } \\
\text { obat FORNAS yang tersedia }\end{array}$ & $100 \%($ Permenkes, 2016) \\
\hline & $\begin{array}{l}\text { 2. Kesesuaian item obat } \\
\text { yang tersedia di FRS }\end{array}$ & $\begin{array}{l}\text { Untuk mengetahui jumlah obat } \\
\text { formularium RS yang tersedia }\end{array}$ & 80\%(Permenkes, 2014) \\
\hline \multirow[t]{6}{*}{ Pengadaan } & $\begin{array}{l}\text { 1. Persentase alokasi Dana } \\
\text { pengadaan obat yang } \\
\text { tersedia. }\end{array}$ & $\begin{array}{l}\text { Untuk mengetahui seberapa } \\
\text { jauh persediaan dana RS } \\
\text { memberikan dana kepada } \\
\text { IFRS }\end{array}$ & $30-40 \%{ }^{(\text {Depkes, }}$ 2008) \\
\hline & $\begin{array}{l}\text { 2. Persentase modal dana } \\
\text { yang tersedia dengan } \\
\text { keseluruhan dana yang } \\
\text { dibutuhkan. }\end{array}$ & $\begin{array}{l}\text { Untuk mengetahui sejauh } \\
\text { mana persediaan dana rumah } \\
\text { sakit memberikan dana } \\
\text { kepada farmasi }\end{array}$ & $100 \%$ (Depkes, 2008) \\
\hline & $\begin{array}{l}\text { 3. Frekuensi kurang } \\
\text { lengkapnya SP/Faktur. }\end{array}$ & $\begin{array}{l}\text { Untuk mengetahui berapa kali } \\
\text { terjadi kesalahan faktur }\end{array}$ & $\begin{array}{l}\text { 1-9 kali(Pudjaningsih, } \\
\text { 1996) }\end{array}$ \\
\hline & $\begin{array}{l}\text { 4. Frekuensi pengadaan } \\
\text { tiap item obat pertahun. }\end{array}$ & $\begin{array}{l}\text { Untuk mengetahui berapa kali } \\
\text { obat -obat tersebut dipesan } \\
\text { dalam setahun }\end{array}$ & $\begin{array}{l}\text { Rendah }<12 \\
\text { x/tahun } \\
\text { Sedang } \\
\text { 24x/tahun } \\
\text { Tinggi >24x/tahun } \\
\text { dibandingkan } \\
\text { EOQ(Pudjaningsih, } \\
\text { 1996) }\end{array}$ \\
\hline & $\begin{array}{l}\text { 5. Frekuensi tertundanya } \\
\text { pembayaran oleh rumah } \\
\text { sakit terhadap waktu } \\
\text { yang disepakati. }\end{array}$ & $\begin{array}{l}\text { Untuk mengetahui kualitas } \\
\text { pembayaran oleh rumah sakit }\end{array}$ & $\begin{array}{l}0-25 \text { kali(Pudjaningsih, } \\
\text { 1996) }\end{array}$ \\
\hline & $\begin{array}{l}\text { 6. Persentase kesesuaian } \\
\text { antara perencanaan obat } \\
\text { dengan kenyataan } \\
\text { masing-masing obat. }\end{array}$ & $\begin{array}{l}\text { Untuk mengetahui ketepatan } \\
\text { perencanaan }\end{array}$ & $\begin{array}{l}100- \\
120 \% \text { (Pudjaningsih, } \\
1996)\end{array}$ \\
\hline \multirow[t]{5}{*}{ Distribusi } & $\begin{array}{l}\text { 1. Ketepatan data jumlah } \\
\text { obat pada kartu stok. }\end{array}$ & $\begin{array}{l}\text { Untuk mengetahui ketelitian } \\
\text { petugas gudang }\end{array}$ & $\begin{array}{l}\text { 100\%(Pudjaningsih, } \\
1996)\end{array}$ \\
\hline & 2. Turn Over Ratio (TOR). & $\begin{array}{l}\text { Untuk mengetahui perputaran } \\
\text { modal dalam satu tahun } \\
\text { persediaan }\end{array}$ & $\begin{array}{l}\text { 10- } \\
\text { 23kali(Pudjaningsih, } \\
\text { 1996) }\end{array}$ \\
\hline & $\begin{array}{l}\text { 3. Persentase dan nilai obat } \\
\text { yang kadaluarsa dan } \\
\text { atau rusak. }\end{array}$ & $\begin{array}{l}\text { Untuk mengetahui besarnya } \\
\text { kerugian Rumah Sakit }\end{array}$ & $\begin{array}{l}0-0,25 \% \text { (Pudjaningsih, } \\
\text { 1996) }\end{array}$ \\
\hline & 4. Persentase stok mati. & $\begin{array}{l}\text { Untuk mengetahui item obat } \\
\text { selama } 3 \text { bulan tidak terpakai }\end{array}$ & 0\%(Depkes, 2008) \\
\hline & $\begin{array}{l}\text { 5. Tingkat ketersediaan } \\
\text { obat. }\end{array}$ & $\begin{array}{l}\text { Untuk mengetahui kisaran } \\
\text { kecukupan obat }\end{array}$ & $\begin{array}{l}\text { 12-18 bulan(Depkes, } \\
\text { 2008) }\end{array}$ \\
\hline \multirow[t]{4}{*}{ Penggunaan } & $\begin{array}{l}\text { 1.Jumlah item obat } \\
\text { perlembar resep. }\end{array}$ & $\begin{array}{l}\text { Untuk mengukur derajat } \\
\text { Polifarmasi }\end{array}$ & $3,3^{(\mathrm{WHO}, 1993)}$ \\
\hline & $\begin{array}{l}\text { 2. Persentase peresepan } \\
\text { dengan nama generik. }\end{array}$ & $\begin{array}{l}\text { Untuk mengukur peresepan } \\
\text { obat generik. }\end{array}$ & $82-94 \%(\mathrm{WHO}, 1993)$ \\
\hline & $\begin{array}{l}\text { 3. Persentase peresepan } \\
\text { obat antibiotik. }\end{array}$ & $\begin{array}{l}\text { Untuk mengukur penggunaan } \\
\text { antibiotika. }\end{array}$ & 22,7WHO,1993) \\
\hline & $\begin{array}{l}\text { 4.Persentase peresepan } \\
\text { obat injeksi. }\end{array}$ & $\begin{array}{l}\text { Untuk mengukur penggunaan } \\
\text { injeksi }\end{array}$ & 17\%WHO,1993) \\
\hline
\end{tabular}




\begin{tabular}{|c|c|c|c|}
\hline Tahapan & Indikator & Tujuan & Nilai Pembanding \\
\hline & $\begin{array}{l}\text { 5. Persentase obat yang } \\
\text { dapat diserahkan. }\end{array}$ & $\begin{array}{l}\text { Untuk mengukur item obat } \\
\text { yang dapat diserahkan }\end{array}$ & $\begin{array}{l}76- \\
100 \% \text { (Pudjaningsih, } \\
1996)\end{array}$ \\
\hline & $\begin{array}{l}\text { 6. Persentase obat yang } \\
\text { dilabeli dengan lengkap. }\end{array}$ & $\begin{array}{l}\text { Untuk mengetahui } \\
\text { penguasaan pengawasan } \\
\text { tentang informasi pokok yang } \\
\text { harus ditulis pada etiket. }\end{array}$ & $\begin{array}{l}100 \% \text { (Pudjaningsih, } \\
\text { 1996) }\end{array}$ \\
\hline & $\begin{array}{l}\text { 7. Rata-rata waktu yang } \\
\text { digunakan } \\
\text { melayani resep. }\end{array}$ & $\begin{array}{l}\text { Mengetahui tingkat kecepatan } \\
\text { pelayanan farmasi dirumah } \\
\text { sakit }\end{array}$ & $\begin{array}{l}\leq 60 \text { menit } \\
\text { racikan } \leq 30 \text { menit } \\
\text { non racikan(Depkes, } \\
\text { 2008) }\end{array}$ \\
\hline
\end{tabular}

\section{Frekuensi pengadaan tiap item obat pertahun}

Frekuensi pengadaan tiap item obat pertahun adalash $4,5-5 \times$ setahun dibandingkan dengan pengadaan melalui metode Economic Order Quantity (EOQ) adalah $14,5 \times$ setahun, ini disebabkan karena rumah sakit yang pemesanannya melalui sistem e-purchasing menggunakan e-katalog pertigabulan sekali ( Permenkes, 2014).

\section{Frekuensi tertundanya pembayaran oleh rumah sakit terhadap waktu yang disepakati}

Frekuensi

tertundanya

pembayaran oleh rumah sakit terhadap waktu yang disepakati adalah 50x artinya melebihi dari standar Pudjaningsih (1996) 0-25 kali, hal ini disebabkan oleh lamanya pembayaran klaim dana BPJS karena pembayaran keuangan oleh rumah sakit menggunakan dana BLUD yaitu dari pemasukan pembayaran klaim BPJS dan pembayaran tunai.

Tabel 2. Hasil Pengamatan

\begin{tabular}{|c|c|c|c|}
\hline Tahapan & Indikator & Jumlah & Standar \\
\hline \multirow[t]{2}{*}{ Seleksi } & 1. Kesesuaian dengan Fornas KFT & $96,7 \%$ & $100 \%($ Permenkes,2016) \\
\hline & 2. Kesesuaian dengan FRS & $86,1 \%$ & $80 \%($ Permenkes, 2015$)$ \\
\hline \multirow{7}{*}{$\begin{array}{l}\text { Perencanaan } \\
\text { dan } \\
\text { pengadaan }\end{array}$} & $\begin{array}{l}\text { 1. Persentase alokasi Dana pengadaan } \\
\text { obat yang tersedia }\end{array}$ & $10,98 \%$ & $30-40 \%$ (Depkes, 2008) \\
\hline & $\begin{array}{l}\text { 2. Persentase modal dana yang tersedia } \\
\text { dengan keseluruhan dana yang } \\
\text { dibutuhkan }\end{array}$ & $54,66 \%$ & $100 \%($ Depkes,2008) \\
\hline & $\begin{array}{l}\text { 3. Frekuensi kurang lengkapnya } \\
\text { SP/Faktur }\end{array}$ & 30 kali & $1-9 \times$ (Pudjaningsih,1996) \\
\hline & 4. Frekuensi kenyataan pengadaan & $4,5 \times$ setahun & Rendah $<12$ x/tahun \\
\hline & $\begin{array}{l}\text { Frekuensi kenyataan pengaadan } \\
\text { menurut } \mathrm{EOQ}\end{array}$ & $14,5 \times$ setahun & $\begin{array}{l}\text { Sedang } \\
\text { 24x/tahun } \\
\text { Tinggi } \\
>24 x^{\text {(Pudjaningsih,1996) }}\end{array}$ \\
\hline & $\begin{array}{l}\text { 5. Frekuensi tertundanya pembayaran } \\
\text { oleh rumah sakit terhadap waktu yang } \\
\text { disepakati }\end{array}$ & $50 x$ & $0-25 \times$ (Pudjaningsih,1996) \\
\hline & $\begin{array}{l}\text { 6. Persentase kesesuaian antara } \\
\text { perencanaan obat dengan kenyataan } \\
\text { masing-masing obat }\end{array}$ & $120,64 \%$ & $\begin{array}{l}100-120 \% \\
\text { (Pudjaningsih,1996) }\end{array}$ \\
\hline
\end{tabular}




\begin{tabular}{|c|c|c|c|}
\hline Tahapan & Indikator & Jumlah & Standar \\
\hline \multirow[t]{5}{*}{ Distribusi } & $\begin{array}{l}\text { 1. Ketepatan data jumlah obat pada } \\
\text { kartu stok }\end{array}$ & $73 \%$ & $100 \%$ (Pudjaningsih,1996) \\
\hline & 2. Turn Over Ratio (TOR). & 4,01 kali & $\begin{array}{l}\text { 10-23x/pertahun } \\
\text { (Pudjaningsih, 1996) }\end{array}$ \\
\hline & $\begin{array}{l}\text { 3. Persentase dan nilai obat yang } \\
\text { kadaluarsa dan atau rusak }\end{array}$ & $2,8 \%$ & $\begin{array}{l}0-0,25 \% \text { (Pujadningsih, } \\
1996)\end{array}$ \\
\hline & 4. Persentase stok mati & $4 \%$ & $0 \%($ Depkes,2008) \\
\hline & 5. Tingkat ketersediaan obat & 13,71 bulan & $\begin{array}{ll}12-18 & \text { bulan } \\
\text { (Depkes,2008) }\end{array}$ \\
\hline \multirow[t]{7}{*}{ Penggunaan } & 1. Jumlah item obat perlembar resep & 3,48 & $\begin{array}{l}1,3-2,2^{(\text {WHO.1993) }} \\
3,3^{\text {(Quck, } 1997)}\end{array}$ \\
\hline & $\begin{array}{l}\text { 2. Persentase peresepan dengan nama } \\
\text { generik }\end{array}$ & $90,91 \%$ & $82-94 \%(\mathrm{WHO}, 1993)$ \\
\hline & 3. Persentase peresepan obat antibiotik & $11,78 \%$ & $22,70 \%(\mathrm{WHO}, 1993)$ \\
\hline & 4. Persentase peresepan obat injeksi & $22,73 \%$ & $\begin{array}{l}\text { Seminal } \\
\text { mungkin (WHO, 1993) } \\
17 \%(\text { Quick,1997) }\end{array}$ \\
\hline & $\begin{array}{l}\text { 5. Persentase obat yang dapat } \\
\text { diserahkan. }\end{array}$ & $99,02 \%$ & $\begin{array}{l}76-100 \%( \\
\text { Pudjaningsih,1996) }\end{array}$ \\
\hline & $\begin{array}{l}\text { 6. Persentase obat yang dilabeli dengan } \\
\text { lengkap }\end{array}$ & $100 \%$ & $100 \%(\mathrm{WHO}, 1993)$ \\
\hline & $\begin{array}{l}\text { 7. Rata-rata waktu yang digunakan } \\
\text { untuk melayani resep }\end{array}$ & $\begin{array}{l}08.00-10.00 \\
\text { Racikan (12 } \\
\text { menit) } \\
\text { Non racikan (5 } \\
\text { menit) } \\
10.00-12.00 \\
\text { Racikan (16 } \\
\text { menit) } \\
\text { Non racikan (7 } \\
\text { menit) } \\
12.00-14.00 \\
\text { Racikan (11 } \\
\text { menit) } \\
\text { Non racikan (5 } \\
\text { menit) }\end{array}$ & $\begin{array}{l}\leq 60 \text { menit racikan } \\
\leq 30 \quad \text { menit non } \\
\text { racikan(Depkes,2008) }\end{array}$ \\
\hline
\end{tabular}

\section{Persentase kesesuaian antara perencanaan obat dengan masing - masing obat}

Persentase

kesesuaian

perencanaan obat melebihi $100-120 \%$ yaitu $120,64 \%$ hal ini berarti perencanan obat masih perlu sedikit diperbaiki karena banyaknya dokter yang minta obat di luar perencanaan dan masih disetujui oleh IFRS sehingga terjadi pemborosan dimana obat yang sudah dipesan tidak dapat terpakai lagi.

\section{Distribusi}

Ketepatan data jumlah obat pada kartu stok

Ketepatan data jumlah obat belum sesuai antara jumlah fisik obat dengan kartu stok adalah $73 \%$, hal ini dapat dikatakan bahwa administrasi 
digudang belum dilaksanakan secara optimal dan efisien karena Sistem Informasi Manajemen (SIM) yang digunakan belum optimal sehingga petugas gudang membutuhkan waktu yang lama dapat mencocokkan antara stok dan fisik obat melalui sistem kadang-kadang para petugas memilih untuk menggunakan metode manual.

\section{Turn Over Ratio (TOR)}

Nilai ITOR IFRSUD Provinsi NTB adalah 4,01 kali/pertahun masih rendah, dan belum sesuai standar dengan indikator Pudjaningsih (1996) yaitu 10-23 kali, hal ini dapat diartikan bahwa secara ekonomi jumlah nilai persediaan belum efisien dan kerugian yang dapat terjadi yaitu dibutuhkannya ruangan penyimpanan obat yang lebih besar dan resikonya obat dapat tertumpuk dan rusak.

\section{Persentase dan nilai obat yang kadaluarsa dan atau rusak}

Persentase nilai obat

kadaluarsa dan rusak sebesar 2,8\% dimana nilai tersebut tidak sesuai dengan standar indikator Pudjaningsih (1996) 0-0,25\%. Dari hasil wawancara dengan bagian pengadaan dan kepala gudang hal ini disebabkan karena kurangnya ketelitian para pegawai IFRS dalam mencatat obat kadaluarsa dan stok opname, dan dalam pengadaan obat pada tahun 2017 tidak memperhatikan RKO pada tahun sebelumnya, sehingga ada sebagian obat yang kadaluarsa/rusak.

\section{Persentase stok mati}

Persentase stok mati sebesar $4 \%$. Hasil yang diperoleh lebih tinggi dibandingkan dengan standar Depkes (2008) yaitu 0\%. Dari hasil wawancara dengan petugas gudang hal ini disebabkan karena kurangnya ketelitian para pegawai IFRS dalam mencatat obat kadaluarsa dan stok opname, dan dalam pengadaan obat pada tahun 2017 tidak memperhatikan RKO pada tahun sebelumnya, sehingga ada sebagian obat yang kadaluarsa/rusak, hal ini dapat terjadi juga karena persentase kesesuaian antara perencanaan obat dengan kenyataan pakai yang besar yaitu melebihi 120,64\% melebihi standar $100-120 \%$ sehingga banyak obat yang mengalami stok mati, sama halnya juga bisa menyebabkan obat rusak dan kadaluarsa.

\section{Tingkat ketersediaan obat}

Tingkat ketersediaan obat di IFRSUD Provinsi NTB sebesar 13,71 bulan dan sudah sesuai standar menurut Depkes RI (2008) sebesar 1218 bulan, dimana dana pengadaan obat sangat terbatas sehingga mempengaruhi tingkat ketersediaan obat, tingkat ketersediaan ini sudah sesuai standar tetapi belum efisien karena tingkat ketersediaan yang banyak atau cukup tetapi belum dikelola dengan baik dan merata sehingga ada yang menumpuk di slah satu depo farmasi.

\section{Penggunaan Jumlah item obat perlembar resep \\ Rata-rata jumlah item obat perlembar resep di IFRSUD Provinsi NTB yaitu sebesar 3,3 yang menunjukkan bahwa terdapat indikasi polifarmasi. Jika dibandingkan dengan}


standar yang ditetapkan Quick yaitu sebesar 3,3 maka dapat dikatakan bahwa pengelolaan obat di IFRSUD Provinsi NTB masih belum sesuai standar karena tiap lembar resepnya masih terdapat lebih resep obat dari standar. Dalam hal ini bisa disebabkan juga karena pasien mempunyai beberapa komplikasi penyakit.

\section{Persentase peresepan dengan nama generik}

Persentase obat dengan nama generik yang diresepkan di RSUD Provinsi NTB menunjukkan angka sebesar 90,91\%. Jika dibandingkan dengan standar yang ditetapkan oleh WHO (1993) yaitu sebesar 82-94\% karena maka di RSUD Provinsi NTB penggunaan obat generik sudah sesuai standar hal ini disebabkan oleh adanya kesadaran dokter untuk menulis resep generik di fasilitas pelayanan kesehatan pemerintah. Hal ini menandakan kerjasama yang baik antara profesi lain agar bisa mendukung lancaranya pelayanan farmasi pada pasien.

Persentase peresepan obat antibiotik Persentase peresepan antibiotik di RSUD Provinsi NTB sebesar $11,78 \%$ lebih rendah dibandingkan WHO (1993) adalah sebesar $22,7 \%$. Persentase peresepan menunjukkan hasil yang relatif efisien dan hal ini disebabkan oleh kesadaran dokter untuk menulis antibiotik sudah bagus. Persentase peresepan antibiotik ini sudah sesuai dengan rekomendasi WHO dimana dokter tidak mudah meresepkan antibiotik untuk setiap diagnosis penyakit.
Persentase peresepan obat injeksi.

Persentase peresapan obat injeksi dirawat inap sebesar 22,73\% lebih tinggi dari standar di Indonesia adalah $17 \%$. Dari hasil wawancara dan pengamatan yang menggunakan injeksi bisa dilihat dari keadaan pasien atau dari penyakitnya, misal untuk pasien di IGD, pasien yang mual dan muntah, sehingga menyebabkan banyaknya penggunaan injeksi. Untuk meminimalisisr penggunaan injeksi yang terlalu banyak, pasien dari IGD yang sudah dipindahkan di bangsal apabila keadaan sudah membaik tetapi masih harus rawat jalan dapat diberikan obat oral saja untuk mengurangi pemakaian injeksi.

\section{Rata-rata waktu yang digunakan} untuk melayani resep

Rata-rata waktu pelayanan resep yang digunakan mulai dari resep masuk sampai penyerahan obat kepada pasien rawat jalan dibagi menjadi 3 waktu yaitu dari pukul 08.0010.00 WITA untuk resep racikan 12 menit, resep non racikan 5 menit. Pukul 10.00-12.00 untuk resep racikan 16 menit, non racikan 7 menit. Pukul 12.00-14.00 untuk resep racikan 11 menit, resep non racikan 5 menit. Ratarata waktu tunggu di IFRSUD Provinsi NTB sudah sesuai dengan standar indikator Depkes (2008) yaitu resep racikan $\leq 60$ menit dan resep non racikan $\leq 30$ menit.

\section{Persentase obat yang dapat diserahkan}

Persentase obat yang dapat diserahkan di IFRSUD Provinsi NTB yaitu $99,02 \%$, sudah memenuhi standar 
Pudjaningsih yaitu 76-100\% (1996). Dari hasil wawancara dengan petugas depo ada beberapa resep yang ditulis dokter tidak termasuk dalam Formurium Nasional dan Formularium Rumah Sakit karena obatnya tidak tersedia IFRSUD Provinsi NTB sehingga diberikan copy resep, sedangkan berdasarkan Permenkes No.28 tahun 2014 bisa diberikan setelah ada rekomendasi dari ketua KFT dengan persetujuan Komite medik atau Kepala/Direktur Rumah Sakit, jika disetujui maka semua pasien diberikan obat tersebut (walaupun harus menunggu beberapa hari) dan pasien dihubungi kembali untuk mengambil obat tersebut.

\section{Persentase obat yang dilabeli dengan lengkap}

Persentase obat dilabeli dengan benar adalah $100 \%$ artinya nilai tersebut sudah memenuhi standar yang ditetapkan yaitu 100\% (WHO,1993). $\mathrm{Hal}$ ini menandakan para pegawai di setiap depo IFRSUD Provinsi NTB telah melabeli etiket dengan benar, selain itu sebelum obat diserahkan kepada pasien selalu dilakukan pengecekan kembali oleh apoteker sehingga dapat mengurangi kesalahan dalam memberi label pada etiket.

\section{Managemen Pendukung Organisasi}

Instalasi farmasi merupakan bagian dari rumah sakit, hal yang perlu diperhatikan dalam suatu organisasi yaitu rumah sakit adanya faktor pengalaman dalam membangun pekerjaan yang sama, dan peran serta semua bagian dalam rumah sakit untuk mensukseskan Sistem Informasi Manajemen yang akan dibangun, dengan adanya integrasi antar semua bagian rumah sakit menjadi satu kesatuan, akan membuat sistem berjalan dengan efektif dan efisien sehingga kendala-kendala seperti redudansi, re-entry dan tidak konsisten pada data dapat dihindarkan, dengan harapan pengguna sistem memperoleh manfaat yang dapat dirasakan secara langsung. Berdasarkan hasil pengamatan, penggunaan manajemen strategis masih pada tingkat rumah sakit. Instalasi farmasi sudah mempunyai visi dan misi tersendiri yang mencerminkan peran serta pelayanan di rumah sakit.

\section{Keuangan}

Hasil pengamatan untuk dana yang disediakan rumah sakit masih sangat minim untuk pembelian obat. Pendapatan khusus di IFRS Umum Provinsi NTB sekarang ini tidak ada untuk pasien BPJS, karena pembayaran menggunakan sistem paket sedangkan untuk pasien umum sudah sangat sedikit dan tidak dilakukan pengamatan/pengambilan data.

\section{Sistem Informasi Manajemen}

Sistem Manajemen Informasi di RSUD Provinsi NTB sudah sepenuhnya menggunakan sistem informasi berbasis komputer. Penggunaan sistem informasi di instalasi farmasi meliputi data pasien, data pemakaian obat, daftar harga, data keluar masuk obat/stok otomatis tapi belum optimal penggunaannya, terkadang masih menggunakan cara manual. 


\section{Sumber Daya Manusia}

Sumber daya manusia Di Instalasi Farmasi Rumah Sakit Umum Daerah Propinsi NTB sudah cukup memadai yaitu sebanyak 47 orang yang terdiri dari Apoteker S2 Farmasi Klinik 2 orang, Apoteker S2 Manajemen 1 orang, Apoteker 12 orang, Asisten Apoteker 30 orang dan SMA 2 orang. Dalam meningkatkan kualitas sumber daya manusia rumah sakit memberi kesempatan bagi para anggotanya untuk mengikuti berbagai program seminar pendidikan dan pelatihan baik yang diadakan oleh pihak rumah sakit ataupun dirumah sakit lain dan instansi pendidikan.

\section{KESIMPULAN}

Tahap seleksi yang sudah sesuai standar adalah kesesuaian item obat dengan Formularium RS (86,1\%), tahap perencanaan dan pengadaan yang yang sudah sesuai standar adalah frekuensi pengadaan tiap item obat pertahun (4,5 kali), tahap distribusi yang sudah sesuai standar adalah tingkat ketersediaan obat (13,71 bulan), tahap penggunaan yang sudah sesuai standar adalah persentase peresepan dengan nama generik (90,91\%), persentase obat yang dapat diserahkan $(99,02 \%)$, persentase obat yang dilabeli dengan lengkap (100\%) dan rata-rata waktu yang digunakan melayani resep dibagi menjadi 3 waktu yaitu pukul 08.00-10.00 resep racikan (12 menit) non racikan (4,5 menit); pukul 10.0012.00 resep racikan (16 menit) non racikan (7 menit); pukul 12.00-14.00 resep racikan (11 menit) non racikan (5 menit).

\section{DAFTAR PUSTAKA}

Budiono,S.Suryawati,S.Sulanto,S.D.,1 999,Manajemen Obat Rumah Sakit : Kumpulan Modul,33-36, Program Pendidikan Pascasarjana, Magister manajemen Rumah Sakit, Fakultas Kedokteran, UGM : Yogyakarta.

Departemen Kesehatan RI 1992. Surat Keputusan Menteri Republik Indonesia No.983/MENKES/SK $\mathrm{XI} / 1992$ Tentang Pelayanan Farmasi Ditetapkan Pada Tanggal 28 Desember 2017 Dan Mulai Berlaku Pada Tanggal 1 April 2018.

Departemen Kesehatan RI, 2006. Keputusan Menteri Kesehatan RI Nomor Nomor 189/Menkes/Sk/III/2006 Tentang Kebijakan Obat Nasional. Jakarta.

Departemen Kesehatan RI., 2008 ${ }^{\mathrm{a}}$. Keputusan Menteri Kesehatan RINomor129/Menkes/Sk/II/200 8 Tentang Standar Pelayanan Minimal Rumah Sakit, Departemen Kesehatan Republik Indonesia, Jakarta

Departemen Kesehatan RI., 2008 Pedoman Perbekalan Farmasi di Rumah Sakit, Direktorat Jedral Pelayanan Kefarmasian dan Alat Kesehatan Departemen Kesehatan Republik Indonesia, Jakarta.

Departemen Kesehatan RI., 2009, Undang-Undang no.44 tentang 
Rumah Sakit, Direktorat Jedral Pelayanan Kefarmasian dan Alat Kesehatan Departemen Kesehatan Republik Indonesia, Jakarta.

Departemen Kesehatan RI., 2010, Keputusan Menteri Kesehatan Republik Indonesia Nomor 1455/MENKES/SK/2010 tentang Formularium Program Jaminan Kesehatan Masyarakat, Departemen Kesehatan Republik Indonesia, Jakarta.

Costa da Inacio, 2017. Evaluasi pengelolaan obat di Instalasi Farmasi RSUD Ungaran Kabupaten Semarang Tahun 2016, Jawa Tengah.

Fakhriadi A., Marchaban., dan Pudjaningsih D. 2011, Analisis Pengengelolaan Obat Di Instalasi Farmasi Rumah Sakit Pku Muhammadiyah Temanggung Tahun 2006, 2007 Dan 2008, Journal Of Management And Pharmacy Practice.

Kemenkes RI., 2014, Tentang Standar Pelayanan Farmasi di Rumah Sakit, Keputusan Menteri Kesehatan Republik Indonesia No. 58 Tahun 2014, Direktorat Jendral Pelayanan Kefarmasian dan Alat Kesehatan, Jakarta.

Kemenkes RI., 2016, Tentang Standar Pelayanan Farmasi di Rumah Sakit, Keputusan Menteri Kesehatan Republik Indonesia
No. 72 Tahun 2016, Direktorat Jendral Pelayanan Kefarmasian dan Alat Kesehatan, Jakarta.

Pudjaningsih., D, 2006,
Pengembangan $\quad$ Indikator
Efisiensi Pengelolaan Obat di
Farmasi Rumah Sakit. Jurnal
Logika 3.16-25.

Permenkes Rl., 2010, Tentang Kewajiban Menggunakan Obat Generik Di Fasilitas Pelayanan Kesehatan Pemerintah. Peraturan Menteri Kesehatan Republik Indonesia No. HK.02.02/Menkes/068/2010. Menteri Kesehatan Republik Indonesia, Jakarta.

Permenkes RI., 2013, Tentang Petunjuk Pelaksanaan Pengadaan Obat Dengan Prosedur E-Purchasing Berdasarkan E-catalogue, Peraturan Menteri Kesehatan Republik Indonesia No. 48 Tahun 2013, Menteri Kesehatan Republik Indonesia, Jakarta.

Permenkes RI., 2011, Tentang Sistem Informasi Rumah Sakit (SIRS) nomor 1171/Menkes/PER/VI/ 2011, Menteri Kesehatan Republik Indonesia, Jakarta.

Quick D.J., Raukin J.R., Laing, RO., O'Conner RW., Horgerzeil,H.V., Dukes,M.N.G and Garnet, A. 1997. Managing Drug Supply 2nd edition, 378-482, , Kumarian Press, West Hartford. 
Quick D.J., Hume, M.L.O., Raukin J.R., Laing, RO., O'Conner RW., 2012. Managing Drug Supply the Selection, Procurement, Distribution, and Use of Pharmaceutical. Second edition. Revised and Expaded, Kumarian Press, West Hartford.

WHO, 1993 Tentang How To Investigate Drug Use In Health Facilities,Selected Drug Use Indicator, Geneva 